\title{
An Exploratory Study On Using Stage Theory To Develop A Data Management Measurement Framework
}

Angela Mattia, Jacksonville University, USA

\begin{abstract}
The issue of interest in this study is two-fold. First the evolution of Nolan's Stage Model is presented. Next, the study discusses adapting Nolan's stage theory into a framework that is an adaptable data management measurement tool. An exploratory measurement tool is developed, tested and refined. This research confirms that a valid measure is possible and that different data management maturity stages have certain characteristics that are important to the emerging knowledge necessary to manage enterprise-wide data as a valuable business resource.
\end{abstract}

Keywords: Data Management; Data Measurement; Stage Model; Data Governance; Data Management Phases

\section{INTRODUCTION}

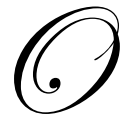

rganizations have long been concerned with acquiring and maintaining their resources. Data, in all its forms (raw data, interpreted data, knowledge, and expertise), is an informational resource that most organizations have had only limited success in managing. High quality data is necessary to meet the ever-changing business environments and master data management must be adaptable to handle the changes (Weber, et al. 2009). Yet, 175 organizations in both the public and private sectors between 2000 and 2006 had an assessment of the data management practices and most of the organizations scored low on the assessment, indicating todays organizations have significant challenges in the area of data management (Aiken, et al. 2007).

Data management is driven by a wide range of concerns, such as new database technologies, changes in work organizations, and social and economic reactions to a changing world. During this formative period of data management development, theories can be particularly useful. Stage theory (Nolan 1973, 1979) offers useful input into data resource management because it is based on the premise that you can describe a pattern of specific stages that elements in systems move through over time. Distinct stage descriptions can become a conceptual framework for development. Nolan's (1979) stage model is one of the best-known frameworks for describing the typical developmental patterns of data processing in organizations. Indeed, during the 1980s and 1990s, it was regarded as a valuable empirically-based theory and accepted description of managing technological change over time (Mahmood \& Becker 1985; Saaksjarvi 1985).

In the present study, a modified version of stage theory is applied to develop an updated measure of data administration practices that organizations will use to move through a pattern of distinct data management maturity phases over time. This maturity pattern can be used to produce guidelines for better data management practices. Therefore, this study contributes to the emerging knowledge necessary to manage enterprise-wide data as a valuable business resource. This is done by investigating the relationships between stage theory and four data administration procedures - enterprise data integration, data stewardship, data development, and data support operations. The results of the investigation are used to develop a data management measure that can help guide the organization's progress toward achieving the optimal combination of data management practices. 


\section{STAGE THEORY}

Nolan's four-stage concept, introduced in 1973, was the theoretical background that allowed others to formulate empirically testable research studies. This study investigated the use of computers and financial resources allocated to using them. The financial resources allocated were quantified by using an organizations computer budget. The Nolan study interpreted experiences and discussions with various computer managers, and then he empirically measured computer budgets in three computers companies. Nolan's identified computer tasks and their relationship to the hypothesized stages, becoming the variables that would form the foundation of his general descriptions of the stages for managing the computer. Nolan's 1973 four stages were: initiation, contagion, control, and integration.

Lucas \& Sutton (1977) was the first test of the stage hypothesis. Twenty-nine firms were studied, examining the issue of the S-Shaped Budget curve. This studied rejected the stage hypothesis, suggesting that a budget was not the appropriate variable to study stage theory and that continued research using other variables was needed. Two years later, Nolan's earlier four-stage version was enhanced in Nolan's 1979 article "Managing the Crises in Data Processing" to reveal a more extensive growth model. This six stage model was developed based on a series of studies that Nolan had done on 3 large corporations, 35 companies and a large number of IBM customers. Nolan probed the status of the data processing activities and developed technological benchmarks that would provide insight. Nolan's 1979 has six stages: initiation, contagion, control, integration, data administration and maturity. The evolution of data processing affects all areas of an organization, and has proven to have significant implications for the overall health of the company.

During the early 1980's, Nolan's Stage Model achieved a high level of interest and acceptance among practitioners (Saaksjarvi 1985) and became an influential concept in academic literature (Benbasat, et al. 1984; Huff, et al. 1988). The early stage hypothesis studies studied different issues using adaptations of the theoretical framework postulated by Nolan. Studies from 1973 - 1981 presented only partial views of the empirical evidence using the stage hypothesis as a framework (Benbasat, et al. 1984). Some had no empirical evidence at all. Findings revealed mixed results, some confirming and some rejecting the stage hypothesis. In addition, the combination of the correct benchmarks to measure organizational maturity was found to be elusive and made measuring maturity difficult.

Using the stage hypothesis, Mahmood and Becker (1985) conducted an empirical study of 59 organizations and 118 managers designed to relate user satisfaction to organizational maturity. This relationship was important because it had long been considered an important part of information systems implementation success. This study is closely related to the present study because an instrument was designed. This instrument measured the maturity of user satisfaction and lead to the reduction of problems between information systems and users. Two questionnaires were used; one with variables that measure each data management maturity stage and the other contained 22 variables to measure user satisfaction. Findings were mixed, showing a significant but weak overall relationship between maturity and user satisfaction. This study was very useful because it leads us to the present study, where 5 stages of organizational maturity are defined.

Today, stage hypothesis studies merge with other theories to use adaptations of the theoretical framework postulated by Nolan. Studies from $2005-2011$ presented empirical evidence using the stage hypothesis as part of its conceptual foundation (Aiken, et al. 2007; Leem, et al. 2008; Reimers, et al. 2009; Sen \& Sinha 2011; SolliSæther \& Gottschalk 2008). Findings revealed from previous studies that the stage hypothesis has evolved over time, but the correct benchmarks to measure organizational maturity continue to be elusive, thus making measuring maturity difficult.

A comprehensive look at how data management is practiced worldwide was conducted by Akien, et al (2007). This study reveals that most organizations continue to not manage data well. In this study, an assessment of the data management practices of 175 organizations, in both the public and private sectors between 2000 and 2006, confirmed that many organizations need more agile methods that allow them to reach higher levels of maturity. These results of this study are important because good data management practices are crucial to many technologybased organizational initiatives, such as data warehousing, web-databases, business intelligence, and other business 
analytics capabilities in today's organizations. The research presented in this study is very useful because it leads us to the present study, where five stages of organizational maturity are defined. The stages of the present study are described in Table 1.

Table 1: The Data Management Maturity Framework (Adapted from Aiken, et al. 2007; Nolan 1979)

\begin{tabular}{|c|c|c|c|c|}
\hline Initial (I) & Repeatable (II) & Defined (III) & Managed (IV) & Optimizing (V) \\
\hline $\begin{array}{l}\text { Applications of data } \\
\text { administration } \\
\text { practices are } \\
\text { encouraged, in each } \\
\text { functional area, } \\
\text { typically at the } \\
\text { application level. }\end{array}$ & $\begin{array}{l}\text { Data administration } \\
\text { activities based on the } \\
\text { needs of management } \\
\text { control and planning as } \\
\text { opposed to the needs } \\
\text { of consolidation and } \\
\text { coordination in the } \\
\text { activities themselves. }\end{array}$ & $\begin{array}{l}\text { Transition into this } \\
\text { stage takes place when } \\
\text { high quality data } \\
\text { services are being } \\
\text { reliably provided to } \\
\text { users. }\end{array}$ & $\begin{array}{l}\text { Data administration } \\
\text { management is } \\
\text { introduced. }\end{array}$ & $\begin{array}{l}\text { The data is complete } \\
\text { and accurate, and its } \\
\text { structure "mirrors" the } \\
\text { organization and the } \\
\text { information flows in } \\
\text { the company. }\end{array}$ \\
\hline \multicolumn{5}{|c|}{ Benchmarks of data administration practices. } \\
\hline $\begin{array}{l}\text { Develop a point-to- } \\
\text { point data interface. } \\
\text { Tool level support } \\
\text { exists. Data support } \\
\text { operations are at the } \\
\text { application level. } \\
\text { Data quality problems } \\
\text { identified \& corrected } \\
\text { by individual } \\
\text { knowledge workers } \\
\text { without additional } \\
\text { guidance. }\end{array}$ & $\begin{array}{l}\text { A project procedure is } \\
\text { initiated for requesting } \\
\text { it. Departments copy } \\
\text { each other's efforts. A } \\
\text { procedure for defining } \\
\text { data exists at the } \\
\text { project level. Data } \\
\text { support operations are } \\
\text { at the departmental. } \\
\text { Data quality problems } \\
\text { identified \& corrected } \\
\text { by procedures } \\
\text { standardized at the } \\
\text { department or unit } \\
\text { level. }\end{array}$ & $\begin{array}{l}\text { Data coordination is } \\
\text { existent but is not } \\
\text { followed. There exists } \\
\text { an enterprise standard } \\
\text { means of requesting it } \\
\text { (by pulling). There } \\
\text { exists a standard means } \\
\text { of obtaining this } \\
\text { support (pull). Exists } \\
\text { for each department or } \\
\text { unit. Exists for each } \\
\text { department or unit. } \\
\text { Data support } \\
\text { operations are at the } \\
\text { enterprise level. }\end{array}$ & $\begin{array}{l}\text { Used effectively } \\
\text { according to metrics } \\
\text { gage the organization } \\
\text { observes data } \\
\text { integration patterns } \\
\text { and actively manages } \\
\text { them - pushing data to } \\
\text { the right knowledge } \\
\text { workers. A data } \\
\text { steward council } \\
\text { manages issues and } \\
\text { evolution. Data } \\
\text { Support Operations are } \\
\text { at the coordinating } \\
\text { council. }\end{array}$ & $\begin{array}{l}\text { Revisable with a } \\
\text { change process that } \\
\text { incorporates feedback. } \\
\text { Active evaluation of } \\
\text { the current state of data } \\
\text { permits proactive } \\
\text { management of } \\
\text { organization data } \\
\text { integration needs } \\
\text { (anticipative- } \\
\text { constantly reevaluates } \\
\text { needs). Active } \\
\text { evaluation of the } \\
\text { integration needs Data } \\
\text { support operations are } \\
\text { at the optimized, } \\
\text { coordinating council. }\end{array}$ \\
\hline
\end{tabular}

Literature on data management typically pays little attention for the need to manage data as a resource. Although many studies involving stage theory have been conducted in information systems and related fields, few have specifically addressed issues involved in data management practices. Consequently, we put these two needs together, investigating data management practices in the present study by using the organizational data management maturity stages as a framework. Managing data as resources requires that the correct data administration practices be in place. The correct practices become a measure of the maturity and a guide that can be used for organizational data management success. It should not prevent change in an organization; it should be a proactive and agile tool to manage it. The present investigation also differs from previous research in that it examines data management practices as four major functions (Table 2) that manage data as a resource (Kahn 1983; Levitin 1998) and use organizational data practices as benchmarks for the data management maturity stage.

While identifying subscales of variables as functions that measure a dimension seems obvious, those who have studied the Nolan's stage model have generally not recognized it. The present investigation also diverges from previous research in that it examines organizational maturity variables realizing that the benchmarks must change with the data administration functions being examined. This reduces the possible bias of a study by investigating them in relation to the four data administration factors developed and the overall maturity. Considering these differences, another purpose of this investigation is to design a measure that data administrators can use to see where their organizations stand in an evolutionary data management process.

Within the context of the above discussion, the objective of the present study was twofold. The first objective was to conduct a preliminary analysis of the empirical construct validity of a survey instrument. This survey instrument is called the Data Maturity Measure (DMM) in this study. A major focus of this analysis included 
an analysis of the dimensionality and internal consistency reliability of the data practices subscales. The second, purpose of the research was to improve and refine the original subscales of data management practices by investigating the relationship of an organization to two key general questions that were asked in the DMM.

1. Are data management activities budgeted according to line items in a manner permitting coordinated management of enterprise data activities?

2. Is there a clearly defined and documented guidance procedure that Data Program Coordinators may use to guide integration, development, stewardship, design, operations, and business data usage?

Table 2: Enterprise Data Management Functions

\begin{tabular}{|l|l|}
\hline \multicolumn{1}{|c|}{$\begin{array}{c}\text { Enterprise Data } \\
\text { Management Functions }\end{array}$} & \multicolumn{1}{c|}{ Descriptors } \\
\hline Enterprise Data Integration & $\begin{array}{l}\text { Data integration points are well defined. } \\
\text { Sharing data across functional boundaries. } \\
\text { Facilities and systems exist supporting group-wide coordination of enterprise data integration } \\
\text { functions (these might include CASE and/or modeling tools, group support, data analysis, etc.) }\end{array}$ \\
\hline Data Stewardship & $\begin{array}{l}\text { Data stewardship functions exist. } \\
\text { A procedure for defining data exists. } \\
\text { Metadata management exists. } \\
\text { Change management exists. } \\
\text { Data quality challenges are managed. }\end{array}$ \\
\hline Data Development & $\begin{array}{l}\text { Database designs from a modeling/architecture perspective. } \\
\text { Organizational level of CASE tool use. }\end{array}$ \\
& $\begin{array}{l}\text { Data quality problems are identified \& corrected. } \\
\text { Active tests performed to determine data quality. } \\
\text { When requesting a new version of a data asset - is the project estimated. }\end{array}$ \\
\hline Data Support Operations & $\begin{array}{l}\text { Level of the organizations policy for doing backup and recovery implemented. } \\
\text { Level of standardization the organization tunes and maintains its databases. }\end{array}$ \\
& $\begin{array}{l}\text { Level of standardization the organization tunes and maintains its disaster recovery effort. } \\
\text { Level of standardization that the organization maintains its data catalog changes. }\end{array}$ \\
\hline Budgeted Data Management & $\begin{array}{l}\text { Data management activities budgeted according to line items in a manner permitting coordinated } \\
\text { management of enterprise data activities. }\end{array}$ \\
\hline $\begin{array}{l}\text { Activities } \\
\text { Defined and Guidance Procedures }\end{array}$ & $\begin{array}{l}\text { Clearly defined and documented guidance procedure that Data Program Coordinators may use to } \\
\text { guide integration, development, stewardship, design, operations, and business data usage. }\end{array}$ \\
\hline
\end{tabular}

Thus, it was determined from past research that budgeted data management activities and defined and documented data management guidance procedures can be key practices in the successful management of data as an organizational resource. Therefore, it is postulated that the variables of budgeted data management activities and defined and documented data management guidance procedures are intricately tied to the overall data management maturity stage of the organization.

Hypothesis 1: An organization that has budgeted data management activities will have progressed to a greater overall data management maturity stage than those without such budgeted data management activities.

Hypothesis 2: An organization that has clearly defined and documented guidance procedures will have progressed to a greater overall data management maturity stage than those without such documented guidance procedures. 


\section{METHOD}

\section{Subjects}

The convenience sample of 35 organizations used in this study included five state agencies, seven federal agencies, 20 public and three international businesses from various sizes and industry descriptions. These organizations were participants in the Annual Data Administrators Conference and had agreed during this conference to participate in this study. There was $100 \%$ participation in the study, eliminating many concerns regarding the threat of selection, and thus to internal validity. Analysis based on a comparison of the descriptive statistics and frequency distributions showed no statistically significant differences between the groups with regard to these demographic variables.

\section{Procedure}

Subjects were contacted by telephone in the months following the Annual Data Administrators Conference and asked a series of questions from the DMM instrument. In all cases, they were informed that the interview was voluntary, and that all responses would be anonymous. This survey instrument was administered as a structured interview during normal working hours over the telephone. The researcher had seven interviewers involved who were chosen because they had no involvement with subjects or the research project goals, thus reducing the threat from experimenter effect. Several meetings were held to explain the DMM instrument and give detailed training on the procedures that would be used to contact the interviewees by telephone. One additional meeting was held to have the interviewers practice conducting a complete telephone interview on each other. These meetings were conducted to reduce possible bias from having multiple interviewers. In all the organizations selected, the contact person was directly involved in the data administration and, therefore, the instrument was relevant to the contact person.

Examples of contact person job title: Systems Architecture, Lead Data Architect, Consultant, Enterprise Architect, Senior Data Architect, HRIS Manager, Computer Specialist, CIO, Sr. Data Modeler, etc..

Data were entered into SPSS and a checklist for data cleansing was used prior to data analysis. The checklist included proofreading, checking for missing data, outliers or non-normal variables.

\section{Data Management Measure (DMM)}

A questionnaire was developed, using a rating scale based on current trends in data administration. The scale construction was an iterative process involving several periods of item writing, followed in each case by analysis of the results. Deductive scale development (Clark \& Watson 1995; Hinkin 1998) was used to generate the maturity scale because of this studies theoretical foundation. The critical first step was to develop a precise measure of the maturity levels of organizations based on their data practices.

The survey (DMM) is comprised of 28 criterion-referenced items divided into six different subscales (data coordination, enterprise data integration, data stewardship, data development, data support operations, and four general questions). There are between four and six items in each subscale. Interviewers asked interviewees to indicate their organizations level of maturity based on the stage indicators placed within the survey. The primary goal of this scale was to maximize validity of our constructs. The data management function questions were then reviewed by a panel of expert judges (faculty and graduate students) who verified their accuracy in terms of data administration trends in current literature (Kahn 1983; Levitin 1998). The questions were adjusted until the expert judges were in agreement supplying evidence of validity based on data management content. As an initial step in using the DMM was to examine an exploratory factor analysis with Direct Oblimin rotation method. The pattern matrix did not demonstrate a clean five-factor solution, resulting in a four-factor scale (enterprise data integration, data stewardship, data development, data support operations, and four general questions) and a reduction in available items for analysis. 


\section{RESULTS}

The dataset was proofread; it appeared accurate with no missing data, outliers or non-normal variables. The frequency distribution for the four composite factors and the overall organizational maturity $(\mathrm{N}=35)$ across the five Nolan stages are shown in Table 3. Table 4 shows the descriptive statistics of the functions. An evaluation of the frequency distributions and descriptive statistics revealed the following characteristics.

Table 3: Frequency Distribution of Nolan Data management maturity stages by Enterprise Data Management Function ( $\mathrm{N}=35)$ (Percentages in Parentheses)

\begin{tabular}{|l|c|c|c|c|c|}
\hline & $\begin{array}{c}\text { Initial } \\
(\mathbf{I})\end{array}$ & $\begin{array}{c}\text { Repeatable } \\
(\text { II) }\end{array}$ & $\begin{array}{c}\text { Defined } \\
(\text { III })\end{array}$ & $\begin{array}{c}\text { Managed } \\
(\text { IV) }\end{array}$ & $\begin{array}{c}\text { Optimizing } \\
(\mathbf{V})\end{array}$ \\
\hline Enterprise Data Integration & $8(23)$ & $11(31)$ & $14(40)$ & $2(6)$ & $0(0)$ \\
\hline Data Stewardship & $10(29)$ & $15(42)$ & $7(20)$ & $3(9)$ & $0(0)$ \\
\hline Data Development & $13(37)$ & $13(37)$ & $8(23)$ & $0(0)$ & $1(3)$ \\
\hline Data Support Operations & $3(9)$ & $19(54)$ & $10(28)$ & $2(6)$ & $1(3)$ \\
\hline Total DA maturity stage & $8(23)$ & $19(54)$ & $8(23)$ & $0(0)$ & $0(0)$ \\
\hline
\end{tabular}

1. The sample of organizations spanned entire range of stages, from initial to optimizing, for two of the enterprise data management functions (Data Development \& Data Support Operations). The span for Enterprise Data Integration, and Data Stewardship ranged from initial to managed. Total DA Data management maturity (DMM) stage ranged from initial to defined.

2. Data Development has one organization placed in the optimizing stage. The cluster of the organizations in the defined stage followed by the lack of any organizations in the managed and only one in the optimizing stage lead to a conclusion that it is an outlier.

3. Enterprise Data Integration and Total DA DMM stage distributions exhibited a negative skew, Data Support Operations had a normal curve and the Data Stewardship, and Data Development exhibited a positive or left skew.

Table 4: Descriptive Statistics Means and Standard Deviations

\begin{tabular}{|c|c|c|c|c|c|c|c|c|c|c|}
\hline & & $\begin{array}{l}\text { FeedBack } \\
\text { Procedure }\end{array}$ & $\begin{array}{l}\text { Guidance } \\
\text { Procedure }\end{array}$ & $\begin{array}{c}\text { Budgeted } \\
\text { Data } \\
\text { Activities }\end{array}$ & $\begin{array}{c}\text { Self- } \\
\text { Assessment } \\
\text { /Data } \\
\text { Needs } \\
\end{array}$ & $\begin{array}{c}\text { Enterprise } \\
\text { Data } \\
\text { Integration }\end{array}$ & $\begin{array}{c}\text { Data } \\
\text { Steward- } \\
\text { ship }\end{array}$ & $\begin{array}{c}\text { Data } \\
\text { Develop- } \\
\text { ment }\end{array}$ & $\begin{array}{c}\text { Data } \\
\text { Support } \\
\text { Operations }\end{array}$ & $\begin{array}{c}\text { Total } \\
\text { DA } \\
\text { DMM } \\
\text { stage }\end{array}$ \\
\hline \multirow{2}{*}{$\mathbf{N}$} & Valid & 35 & 35 & 35 & 35 & 35 & 35 & 35 & 35 & 35 \\
\hline & Missing & 0 & 0 & 0 & 0 & 0 & 0 & 0 & 0 & 0 \\
\hline \multicolumn{2}{|c|}{ Mean } & .6286 & .4857 & .5429 & .6286 & 2.5524 & 2.3429 & 2.2667 & 2.7000 & 2.4835 \\
\hline \multicolumn{2}{|c|}{ Median } & 1.0000 & .0000 & 1.0000 & 1.0000 & 2.6667 & 2.0000 & 2.3333 & 2.5000 & 2.5385 \\
\hline \multicolumn{2}{|c|}{$\begin{array}{l}\text { Std. } \\
\text { Deviation }\end{array}$} & .49024 & .50709 & .50543 & .49024 & 1.04770 & .87629 & .93165 & .73963 & .60815 \\
\hline \multicolumn{2}{|c|}{ Variance } & .24034 & .25714 & .25546 & .24034 & 1.09767 & .76788 & .86797 & .54706 & .36985 \\
\hline \multicolumn{2}{|c|}{ Minimum } & $.00(\mathrm{No})$ & $.00(\mathrm{No})$ & $.00(\mathrm{No})$ & $.00(\mathrm{No})$ & .33 & 1.00 & 1.00 & 1.25 & 1.44 \\
\hline \multicolumn{2}{|c|}{ Maximum } & $1.00(\mathrm{Yes})$ & $1.00($ Yes $)$ & 1.00 (Yes) & $1.00($ Yes $)$ & 4.50 & 4.33 & 5.00 & 5.00 & 3.79 \\
\hline
\end{tabular}

4. The mean of the Total DA Data management maturity stage is 2.4835 , two enterprise data management functions (Enterprise Data Integration \& Data Support Operations) have means that are higher and two enterprise data management functions (Data Development \& Data Stewardship) have means that are lower. The means are all in the Repeatable data management maturity stage.

5. Standard Deviation of the Total DA Data management maturity stage is .60815 and all four enterprise data management functions (Enterprise Data Integration, Data Support Operations, Data Development \& Data Stewardship) have Standard Deviations and variance that are higher.

Organizations do not always progress along the enterprise data management variables at the same rate as established by the differences among the frequency distributions. This confirms the findings of many other researchers (Mahmood \& Becker 1985). 
In order to test Hypothesis 1 , that an organization that has $(\mathrm{N}=19)$ budgeted data management activities (independent variable) will have progressed to a greater overall (dependent variable) data management maturity stage than those without $(\mathrm{N}=16)$ such budgeted data management activities, a one-way analysis of variance ANOVA was performed. This ANOVA compared an organization that has budgeted data management activities to those that do not. The $\mathrm{P}$ value was significant at the .02 level, with the organization that has budgeted data management activities progressing to a greater overall data management maturity stage (2.7045) than those without (2.2212). The means, standard deviation and significance level are shown in Table 5.

Table 5: Descriptives

\begin{tabular}{|ll|c|c|c|c|c|}
\hline \multirow{2}{*}{ Budgeted Data Management Activities } & \multirow{2}{*}{ Mean } & \multirow{2}{*}{ Std. Deviation } & \multicolumn{2}{|c|}{ ANOVA } \\
\cline { 4 - 7 } & & & & & F & Sig. \\
\hline $\mathbf{. 0 0}$ & (No) & 16 & 2.2212 & .56866 & & \\
\hline $\mathbf{1 . 0 0}$ & Yes) & 19 & 19 & 2.7045 & 6.348 & .017 \\
\hline
\end{tabular}

Hypothesis 2 was that an organization that has $(\mathrm{N}=17)$ clearly defined and documented guidance procedures would progress to a greater overall data management maturity stage than those without $(\mathrm{N}=18)$ such documented guidance procedures. Testing was conducted with a one-way analysis of variance (ANOVA) with the clearly defined and documented guidance procedure as the independent variable, and the overall data management maturity stage is the dependent variable. This ANOVA compared an organization that has clearly defined and documented guidance procedures to those that do not. The main effect was significant at the .02 level, with the organization that has budgeted data management activities progressing to a greater overall data management maturity stage (2.7421) than those without (2.2393). The means and standard deviation are shown in Table 6 and results of the ANOVA are shown in Table 6.

Table 6: Descriptives

\begin{tabular}{|ll|c|c|c|c|c|}
\hline \multicolumn{2}{|c|}{$\begin{array}{c}\text { Clearly Defined and Documented Guidance } \\
\text { Procedure }\end{array}$} & \multirow{2}{*}{ N } & Mean & \multirow{2}{*}{ Std. Deviation } & \multicolumn{2}{c|}{ ANOVA } \\
\cline { 5 - 7 } & & & & & F & Sig. \\
\hline $\mathbf{. 0 0}$ & $\mathbf{N o})$ & 18 & 2.2393 & .64136 & & \\
\hline $\mathbf{1 . 0 0}$ & $($ Yes $)$ & 17 & 2.7421 & .45908 & 7.036 & .012 \\
\hline
\end{tabular}

The results provided support for the hypothesized relationship between budgeted data management activities, clearly defined and documented guidance procedures and the overall maturity of the organization. The null hypothesis is rejected for both.

Lastly, it is important to put emphasis on the exploratory nature of the DMM. The above results are based on this reduction of items to thirteen and factors to four. This plays a crucial role in ensuring the unidimensionality and discriminate validity of the scale (Clark \& Watson 1995). This item reduction produced a strong 4-factor loading (.602 - .936) and high alpha coefficients $(.6993-.8764)$. This analysis establishes a good foundation for the DMM and is the beginning of the necessary research to establish a valid measurement instrument of organizational data management maturity. The validity of the instrument supports the credibility of the ANOVA results, since it requires one to produce the other.

\section{DISCUSSION}

In the present study, the organizations have mixed placement within the data management maturity framework using the four data administration factors - enterprise data integration, data stewardship, data development, and data support operations as shown by the frequency distribution (Table 3). This was expected because prior research had lead to the same conclusion (Aiken, et al. 2007; Benbasat, et al. 1984). In this study, the clear implications of this frequency distribution are that organizations and the research investigating them is still very immature when it comes to managing data as a resource. The information age is a recent event in history 
coupled with rapid technological growth, impacting all areas of an organization. It has been so explosive that little time or attention has been given to the management of data and even less to its value as a resource (Levitin 1998). Therefore, during this rapid time of changing technology and growth of knowledge development, stage theory (Aiken, et al. 2007; Nolan 1973; Nolan 1979) would be particularly useful in setting guidelines for data resource management as postulated by this research.

This study provides a glimpse into how an organization that has budgeted data management activities will have progressed to a greater overall data management maturity level than those without such budgeted data management activities. From a budget perspective, the results are consistent with Nolan (1979). However, caution is warranted when interpreting the present studies agreement with Nolan because his initial direction was using the S-Shaped Budget curve. The Lucas \& Sutton (1977) study had rejected the stage hypothesis when examining the SShaped Budget curve, and the study suggested that budget was not the appropriate variable for measuring Nolan's stage theory. This study used data management activities budgeted according to line items in a manner permitting coordinated management of enterprise data activities as an independent variable and compared those with to those without much practices. This was determined to be the appropriate independent variable because budgeting data management costs require a proactive budgeting activity be in place (Goodhue, et al. 1992; Kahn 1983). Thus, it was concluded that the nature of the budgeting activity, not the type of budget indicates greater overall maturity.

Additionally, an organization that has clearly defined and documented guidance procedures progressed to a greater overall data management maturity level than those without such documented guidance procedures. It is a clearly defined and documented guidance procedure that Data Program Coordinators may use to guide integration, development, stewardship, design, operations, and business data usage compared to those who do not. In addition, we are reminded this is a characteristic in stage theory formulation; elements change as its attributes expand or contract in number and nature (Nolan, 1973). Guidelines for action (Nolan, 1979) are established to make change a proactive managed process instead of a reactive environmental process.

\section{Research Limitations}

Research suggests that the retention of four - six items for most constructs, although there are no absolute rules guiding this decision (Hinkin 1998). The DMM scale could use additional items to supply the refined construct validity necessary for a good survey instrument. Strong construct validity is very important because a cross-sectional survey instrument only allows for a snapshot in time of organizational maturity. The conclusions based on a cross-sectional survey are tentative because this design could have important differences occurring between organizations. These differences could affect the organizations maturity level, and that could result in inaccurate conclusions.

\section{IMPLICATIONS FOR FUTURE RESEARCH}

The Challenge! Expanding the earlier studies by:

- $\quad$ Capturing the essence of Nolan's Model of stage theory.

- $\quad$ Developing a questionnaire and structure interview that will continue to be refined, as needed.

- $\quad$ Consider and control for intervening variables.

- Investigating more of the general questions in relation to the 4 factors developed and the overall maturity.

- $\quad$ Attempting to overcome the bias of too narrow of samples

- Expanding Cross-sectional measures with the richness of comments and a follow-up longitudinal study.

Some research challenges (Schwab 1999) to the methods used are potential roles of the variables that are not accounted for in the research model investigated. Are the relationships biased? Statistical analysis is being used to control for potential biasing variables, but it important to acknowledge that in this type of research it is a serious concern. 


\section{CONCLUSION}

This study first reviewed and characterized information systems organizational data management maturity stages and data management practices adapted from Nolan's 1979 model. This research was the basis of the data management measurement (DMM) instrument that was then used in an empirical study of 35 organizations designed to relate the defined data management maturity levels with data management practice variables. Factor analysis reduced the variables, but the positive side of this was that keeping the measure short is an effective means of minimizing response biases caused by boredom and fatigue. The data coordination factor would be readdressed to establish validity and dimensionality of that construct. This measure would need refinement to include at least twice as many new items (Hinkin 1998) as would be needed for future confirmatory research. Consequently, allowing for future reduction and further refinement of a solid construct of measurement. Further work must be conducted in order to develop a complete scale of enterprise data management maturity stages and for use in further investigation and testing of this framework.

Nevertheless, the DMM proved to be a valid measure for this exploratory research confirming portions of the measure based on the fact that different data management maturity stages have certain characteristics (Nolan, 1973; Nolan, 1978). The study of the mixed frequency distribution through the five stages, budgeted data activities and clear guidelines establishes that higher levels of maturity can be achieved through this knowledge. These two confirmed hypotheses continued to establish that proactive data management, NOT time, has played a key role in information systems organizations' data effectiveness. Can this knowledge be used to better understand how to navigate the informational explosion of the twenty-first century and gain insight into how to manage data as a resource? In light of the recent studies to treat data as an organizational resource and the importance of the data management in organizations, this study is both timely and significant. However, being exploratory in nature, it should be considered as setting the stage for future work in this domain

\section{AUTHOR INFORMATION}

Angela Mattia is an assistant professor of Decision Sciences and Information Management in the Davis College of Business at Jacksonville University located in Jacksonville Florida. Her research interests include data and systems reengineering and maturity models. Mattia received a Ph.D. in information systems from Virginia Commonwealth University. E-mail: amattia@ju.edu

\section{REFERENCES}

1. Aiken, P., Allen, M. D., Parker, B., \& Mattia, A. (2007). Measuring Data Management Practice Maturity: A Community's Self-Assessment. Computer, 40(4), 42-50.

2. Benbasat, I., Dexter, A. S., Drury, D. H., \& Goldstein, R. C. (1984). A critque of the stage hypothesis: theory and empirical evidence. Commun. ACM, 27(5), 476-485.

3. Clark, L. A., \& Watson, D. (1995). Constructing validity: Basic issues in objective scale development. Psychological assessment, 7(3), 309.

4. Goodhue, D. L., Wybo, M. D., \& Kirsch, L. J. (1992). The impact of data integration on the costs and benefits of information systems. MIS Q., 16(3), 293-311.

5. Hinkin, T. R. (1998). A Brief Tutorial on the Development of Measures for Use in Survey Questionnaires. Organizational Research Methods, 1(1), 104-121.

6. Huff, S. L., Munro, M. C., \& Martin, B. H. (1988). Growth stages of end user computing. Commun. ACM, 31(5), 542-550.

7. Kahn, B. K. (1983). Some realities of data administration. Commun. ACM, 26(10), 794-799.

8. Leem, C. S., Kim, B. W., Yu, E. J., \& Paek, M. H. (2008). Information technology maturity stages and enterprise benchmarking: an empirical study. Industrial Management \& Data Systems, 108(9), 1200-1218.

9. Levitin, A. V. (1998). Data as a resource: Properties, implications, and prescriptions. Sloan Management Review, 40(1), 89-101.

10. Mahmood, M. A., \& Becker, J. D. (1985). Impact of organizational maturity on user satisfaction with information systems.

11. Nolan, R. L. (1973). Managing the computer resource: a stage hypothesis. Commun. ACM, 16(7), 399-405. 
12. Nolan, R. L. (1979). Managing the crisis in data processing. Harvard Business Review, 115-126.

13. Reimers, K., Guo, X., \& Chen, G. (2009). Do IT managers learn how to control spending on new information technology?: a study of IT budget growth in Chinese companies. ACM SIGMIS Database, 40(1), 20-37.

14. Saaksjarvi, M. (1985). End-user participation and the evolution of organizational information systems: an empirical assessment of Nolan's stage model.

15. Schwab, D. P. (1999). Research methods for organizational studies.

16. Sen, A., \& Sinha, A. P. (2011). IT alignment strategies for customer relationship management. Decision Support Systems.

17. Solli-Sæther, H., \& Gottschalk, P. (2008). Maturity in IT outsourcing relationships: an exploratory study of client companies. Industrial Management \& Data Systems, 108(5), 635-649.

18. Weber, K., Otto, B., \& Österle, H. (2009). One Size Does Not Fit All---A Contingency Approach to Data Governance. Journal of Data and Information Quality (JDIQ), 1(1), 4. 